\title{
Effects of a gluten-free diet on gut microbiota and immune function in healthy adult human subjects
}

\author{
Giada De Palma, Inmaculada Nadal, Maria Carmen Collado and Yolanda Sanz* \\ Microbial Ecophysiology and Nutrition Group, Institute of Agrochemistry and Food Technology (IATA), Spanish National \\ Research Council (CSIC), PO Box 73, 46100 Burjassot, Valencia, Spain
}

(Received 13 August 2008 - Revised 3 April 2009 - Accepted 6 April 2009 - First published online 18 May 2009)

Diet influences the composition of the gut microbiota and host's health, particularly in patients suffering from food-related diseases. Coeliac disease (CD) is a permanent intolerance to cereal gluten proteins and the only therapy for the patients is to adhere to a life-long gluten-free diet (GFD). In the present preliminary study, the effects of a GFD on the composition and immune function of the gut microbiota were analysed in ten healthy subjects (mean age 30.3 years) over 1 month. Faecal microbiota was analysed by fluorescence in situ hybridisation (FISH) and quantitative PCR (qPCR). The ability of faecal bacteria to stimulate cytokine production by peripheral blood mononuclear cells (PBMC) was determined by ELISA. No significant differences in dietary intake were found before and after the GFD except for reductions $(P=0.001)$ in polysaccharides. Bifidobacterium, Clostridium lituseburense and Faecalibacterium prausnitzii proportions decreased ( $P=0.007, P=0.031$ and $P=0.009$, respectively) as a result of the GFD analysed by FISH. Bifidobacterium, Lactobacillus and Bifidobacterium longum counts decreased $(P=0.020, P=0.001$ and $P=0.017$, respectively), while Enterobacteriaceae and Escherichia coli counts increased $(P=0.005$ and $P=0.003)$ after the GFD assessed by qPCR. TNF- $\alpha$, interferon- $\gamma$, IL-10 and IL- 8 production by PBMC stimulated with faecal samples was also reduced $(P=0.021, P=0.037, P=0.002$ and $P=0.007$, respectively) after the diet. Therefore, the GFD led to reductions in beneficial gut bacteria populations and the ability of faecal samples to stimulate the host's immunity. Thus, the GFD may constitute an environmental variable to be considered in treated CD patients for its possible effects on gut health.

Intestinal microbiota: Gluten-free diet: Coeliac disease: Immunity

Diet influences the composition and function of the gut microbiota and thereby the host's health, particularly in patients suffering from food-related diseases. Coeliac disease (CD) is an inflammatory disorder of the small intestine caused by a permanent intolerance to gluten proteins in predisposed individuals. In these patients, gluten peptides trigger an abnormal immune response that causes the typical CD tissue lesion characterised by villous atrophy, crypt hyperplasia, and increased numbers of intra-epithelial and lamina propria lymphocytes ${ }^{(1,2)}$. CD enteropathy is sustained by a T-helper (Th)1 immune response with production of pro-inflammatory cytokines (for example, interferon (IFN)- $\gamma$ ), as well as by an innate immune response mediated by IL-15 that activates intra-epithelial lymphocytes and epithelial cell killing ${ }^{(3)}$. Increased production of pro-inflammatory cytokines by cells of the innate immune system (monocytes, macrophages and dendritic cells) is also thought to mediate the recruitment of lymphocytes into the lamina propria and epithelium, thus contributing to the disease ${ }^{(4)}$. The treatment with a gluten-free diet (GFD) usually leads to normalisation of mucosal histology and remission of clinical symptoms. Nevertheless, compliance with this dietary therapy is very complex and patients often suffer from higher health risks and nutritional deficiencies ${ }^{(5,6)}$. The composition and metabolic activity of the intestinal microbiota is currently thought to be involved in a number of chronic inflammatory disorders. Most recent studies indicate that CD patients untreated and treated with a GFD have unbalanced microbiota that can play a pathogenic role or constitute a risk factor for this disorder ${ }^{(7,8)}$. Nevertheless, part of the detected microbial changes could be due not only to the underlying disease but also to the dietary intervention by a GFD in treated CD patients. A GFD has also been tested as dietary treatment for autism ${ }^{(9)}$. However, the possible effect of a GFD in the gut ecosystem remains largely unknown.

The objective of the present study was to analyse the impact of a GFD on the composition and immune function of the microbiota in healthy subjects to gain further insights on interactions between diet and gut microbes, as well as on

Abbreviations: CD, coeliac disease; FISH, fluorescence in situ hybridisation; GFD, gluten-free diet; IFN, interferon; IQR, interquartile range; PBMC, peripheral

blood mononuclear cells; qPCR, quantitative PCR; Th, T-helper.

* Corresponding author: Dr Yolanda Sanz, fax +34 963636301, email yolsanz@iata.csic.es 
the possible effects of this therapy on gut health and quality of life of CD patients.

\section{Experimental methods}

\section{Subjects}

Ten volunteers (eight women and two men; mean age $30 \cdot 3$ years; range 23-40 years) were included in the study. All participants included in the present study had no history of digestive pathology or signs of malnutrition. None of the volunteers had been treated with antibiotics at least within the 2 months before the faecal sampling. Informed consent was obtained from the subjects, and the study was approved by the local ethics committee.

\section{Dietary intervention and assessments}

Subjects were submitted to a GFD by replacing gluten-containing foods by equivalent ones certified as gluten-free (20 parts per million maximum gluten content) by the Spanish Federation of Coeliac Association (FACE) over a 1-month period. Food diary records were kept for $72 \mathrm{~h}$ ( 2 weekdays and 1 weekend day) both before the start of the intervention and after 1 month to monitor dietary changes. At the front of the diary, detailed information on how to record food and beverages consumed using common household measures was provided. When completing the food diary records, subjects were instructed to record everything they ate or drank. Food diary records were returned to the dietitian as soon as possible after completion when they were reviewed, and analysed for energy, water and macronutrient contents based on the CESNID food composition database of Spanish foods ${ }^{(10)}$.

\section{Faecal sampling}

Faecal samples from each adult volunteer were collected before and after following the GFD and processed as described elsewhere in duplicate ${ }^{(7,11)}$. Briefly, $2 \mathrm{~g}$ (wet weight) were 10 -fold diluted in PBS (130 mM-sodium chloride, $10 \mathrm{~mm}$-sodium phosphate, $\mathrm{pH} 7 \cdot 2$ ) and homogenised for 5 min in a Lab Blender 400 stomacher (Seward Medical, London, UK). The homogenised samples were subjected to a low-spin centrifugation $(2000 \mathrm{rpm}, 2 \mathrm{~min})$ to remove large particulate material, and samples of the obtained supernatant fractions were used for either DNA extraction or hybridisation. Before hybridisation, one volume of the supernatant fraction was mixed with three volumes of fresh $4 \%$ paraformaldehyde, fixed at $4^{\circ} \mathrm{C}$ overnight, and stored in $50 \%$ ethanol-PBS at $-80^{\circ} \mathrm{C}$ until use for hybridisation ${ }^{(7,11)}$. DNA extractions were done by using the QIAamp DNA Stool Mini Kit (Qiagen, Hilden, Germany) following the manufacturer's instructions.

\section{Fluorescence in situ hybridisation and flow cytometry detection}

Enumeration of bacteria present in faecal samples was carried by fluorescence in situ hybridisation (FISH) using $16 \mathrm{~S}$ rRNA-targeted oligonucleotide probes (MOLBIOL,
Berlin, Germany), as previously described ${ }^{(7,11)}$. The following probes were used: EUB 338 for the detection of total bacteria $^{(12)}$; Ato291 for Atopobium group ${ }^{(13)}$; Bif164 for Bifidobacterium genus ${ }^{(14)}$; Lab158 for Lactobacillus and other lactic acid bacteria ${ }^{(15)}$; Bac303 for Bacteroides-Prevotella group ${ }^{(16)}$; Ecol1513 for Escherichia coli ${ }^{(17)}$; Erec0482 for Eubacterium rectale-Clostridium coccoides $\operatorname{group}^{(18)}$; CHis159 for $C$. histolyticum group $^{(13)}$; CLis135 for C. lituseburense group ${ }^{(19)}$; Fprau645 for Faecalibacterium prausnitzii $^{(20)}$. Cells were enumerated by combining in the same hybridisation tube one group-specific fluorescein isothiocyanate probe with the EUB 338-Cy3 probe. The proportion of group cells was corrected by eliminating background fluorescence, which was measured using the negative control NON 338 probe $^{(7,21)}$. Fixed cells were incubated in the hybridisation solution (10 mM-2-amino-2-hydroxymethyl-propane-1,3-diol-HCl, $0.9 \mathrm{M}-\mathrm{NaCl}, \mathrm{pH} 8.0$, and $10 \%$ SDS) containing $4 \mathrm{ng} / \mu \mathrm{l}$ of each fluorescent probe at appropriate temperatures overnight, washed and re-suspended in PBS solution for flow cytometric analysis ${ }^{(7,11)}$.

Flow cytometry detections were performed using an EPICS ${ }^{\circledR}$ XL-MCL flow cytometer (Beckman Coulter, Miami, FL, USA) as previously described ${ }^{(7,22)}$. This instrument is equipped with two light scatter detectors that measure forward and side scatter and fluorescence detectors that detect appropriately filtered light at green (FL1; $525 \mathrm{~nm}$ ) and redorange (FL3; $620 \mathrm{~nm}$ ) wavelengths. The event rate was kept at the lowest setting (200-300 events per s) to avoid cell coincidence. A total of 15000 events were recorded in a list mode file and analysed with System II V.3 software (Beckman Coulter). The proportion of each bacterial group was expressed as a ratio of cells hybridising with the fluorescein isothiocyanate-labelled specific probe to cells hybridising with the universal EUB 338-Cy3 probe ${ }^{(7,22)}$.

\section{Quantitative real-time polymerase chain reaction analysis}

Quantitative PCR (qPCR) was used to characterise the composition of the faecal microbiota by the use of specific primers targeting different intestinal bacterial groups as described elsewhere ${ }^{(23,24)}$. PCR amplification and detection were performed with an ABI PRISM 7000-PCR sequence detection system (Applied Biosystems, Warrington, Cheshire, UK). Each reaction mixture of $25 \mu \mathrm{l}$ was composed of SYBR ${ }^{\circledR}$ Green PCR Master Mix (SuperArray Bioscience Corporation, Frederick, MD, USA), $1 \mu$ l of each of the specific primers at a concentration of $0.25 \mu \mathrm{M}$ and $1 \mu \mathrm{l}$ of template DNA. The bacterial concentration from each sample was calculated by comparing the $\mathrm{Ct}$ (cycle threshold) values obtained from standard curves. Standard curves were created using serial 10-fold dilution of pure culture DNA corresponding to $10^{2}$ to $10^{9}$ cells as determined by microscopy counts using 4',6-diamidino-2-phenylindole.

\section{Isolation and stimulation of peripheral blood mononuclear cells}

Peripheral blood mononuclear cells (PBMC) were isolated from heparinised peripheral blood of four healthy volunteers (aged 26-28 years) as previously described ${ }^{(25)}$. Briefly, PBMC were isolated by centrifugation over a Ficoll density 
gradient (Amersham Biosciences, Piscataway, NJ, USA) and adjusted to $1 \times 10^{6}$ cells $/ \mathrm{ml}$ in Roswell Park Memorial Institute (RPMI) 1640 (Cambrex, New York, NY, USA), supplemented with $10 \%$ fetal bovine serum (Gibco, Barcelona, Spain), $2 \mathrm{~mm}-\mathrm{L}-\mathrm{glutamine}$, streptomycin $(100 \mu \mathrm{g} / \mathrm{ml})$ and penicillin $(100 \mathrm{U} / \mathrm{ml})$ (Sigma, St Louis, MO, USA). PBMC were incubated in twenty-four-well flat-bottomed polystyrene microtitre plates (Corning, Madrid, Spain) and incubated at $37^{\circ} \mathrm{C}$ under $5 \% \mathrm{CO}_{2}$. Faecal samples, $30 \mu \mathrm{l}$, of each subject before and after following the GFD were used to stimulate PBMC for $24 \mathrm{~h}$. Purified lipopolysaccharide (LPS) from Escherichia coli O111:B4 (Sigma) was used at a concentration of $1 \mu \mathrm{g} / \mathrm{ml}$ as a positive control. Non-stimulated PBMC were also evaluated as controls of basal cytokine production. All reagents were tested by the E-toxate test for LPS (Sigma) and shown to be below the limit of detection $(2 \mathrm{pg} / \mathrm{ml})$. Every sample used as stimulant was assayed in duplicate. Cell-culture supernatant fractions were collected by centrifugation, fractionated in samples, and stored at $-20^{\circ} \mathrm{C}$ until cytokines were analysed.

\section{Cytokine assays}

Cytokine concentrations of supernatant fractions were measured by ELISA. The pro-inflammatory cytokines TNF- $\alpha$ and IFN- $\gamma$ and the regulatory cytokine IL-10 were analysed by using the Ready SET Go! Kit (eBioscience, San Diego, CA, USA), and the chemokine IL-8 by using a Diaclone ELISA commercial kit (Diaclone, Madrid, Spain), according to the manufacturers' instructions. The sensitivity of assays for each cytokine was as follows: $4 \mathrm{pg} / \mathrm{ml}$ for TNF- $\alpha$ and IFN- $\gamma$, $2 \mathrm{pg} / \mathrm{ml}$ for IL-10 and $<25 \mathrm{pg} / \mathrm{ml}$ for IL-8.

\section{Statistical analyses}

Statistical analyses were done using SPSS 11.0 software (SPSS Inc., Chicago, IL, USA). Dietary composition (mean values and standard deviations) was calculated for crude (unadjusted) nutrients from the $72 \mathrm{~h}$ dietary registers and data were averaged for the analysis. Dietary variables were submitted to log-transformation and mean comparisons before and after the intervention were determined by applying the Student's $t$ test. Microbial data are expressed as medians with interquartile ranges (IQR) and the differences in bacterial counts before and after GFD were determined by applying the Mann-Whitney $U$ test. Results of cytokine production are expressed as means with standard deviations and differences were determined by applying the Student's $t$ test. In every case, $P$ values $<0.05$ were considered statistically significant.

\section{Results and discussion}

Gluten-free diet influences the composition of the intestinal microbiota in healthy subjects

A preliminary study was carried out to establish the effects of a GFD on the composition of the intestinal microbiota and to gain insights into the possible relationship of this dietary therapy with gut health. The adult human subjects included in the study, $80 \%$ female (eight out of ten) and $20 \%$ male (two out of ten), maintained a good health status during the intervention, and followed a conventional diet without any restriction except for gluten-containing products. Dietary data before and after the intervention are shown in Table 1. No significant differences in dietary intake were found in energy and macronutrients as a result of the GFD except for significant reductions $(P=0.001)$ in polysaccharide intake. Previous studies on the nutritional quality of the GFD also indicated that it is associated with reductions in the intake of polysaccharides together with energy compared with the standard gluten-containing diet of healthy individuals, according to the present results ${ }^{(26)}$. The composition of the faecal microbiota under the effects of the GFD determined by FISH is shown in Table 2. Individual baseline variability of bacterial populations expressed as median of differences in proportions of bacterial cells hybridising with group-specific probes related to total bacteria hybridising with EUB probe 338 was as follows: 2.38 (IQR 1.01-5.30) for Atopobium group; 1.86 (IQR 1.42-3.10) for Bifidobacterium; 1.54 (IQR 1.09-2.13) for Lactobacillus group; $2 \cdot 16$ (IQR 0.86-3.26) for Bacteroides-Prevotella; 1.29 (IQR 0.84-1.47) for Escherichia coli; 6.54 (IQR 0.21-10.41) for Eubacterium rectale-C. coccoides; 1.04 (IQR 0.41-2.48) for C. histolyticum; 1.63 (IQR 0.59-3.61) for C. lituseburense; 6.65 (IQR 0.62-6.72) for $F$. prausnitzii. Bifidobacterium, $C$. lituseburense and $F$. prausnitzii proportions decreased significantly $(P=0.007$, $P=0.031$ and $P=0.009$, respectively) as a result of the GFD (Table 2). Lactobacillus group proportions were also almost significantly reduced $(P=0 \cdot 058)$ after the GFD (Table 2).

Table 1. Daily energy and nutrient intake before and after the glutenfree diet (GFD) intervention

(Mean values and standard deviations)

\begin{tabular}{|c|c|c|c|c|}
\hline \multirow[b]{2}{*}{ Diet composition } & \multicolumn{2}{|c|}{$\begin{array}{l}\text { Subjects before } \\
\text { GFD }(n 10)\end{array}$} & \multicolumn{2}{|c|}{$\begin{array}{l}\text { Subjects under } \\
\text { GFD (n10) }\end{array}$} \\
\hline & Mean & SD & Mean & SD \\
\hline \multicolumn{5}{|l|}{ Energy } \\
\hline $\mathrm{kJ}$ & $7759 \cdot 68$ & $1446 \cdot 91$ & 7464.51 & $1263 \cdot 28$ \\
\hline kcal & $1854 \cdot 61$ & $345 \cdot 82$ & $1784 \cdot 06$ & 301.93 \\
\hline Water (g) & 2454.56 & 533.35 & 2764.96 & $464 \cdot 18$ \\
\hline Protein (g) & 72.99 & $15 \cdot 69$ & $68 \cdot 48$ & $13 \cdot 19$ \\
\hline Energy from protein (\%) & $15 \cdot 74$ & $3 \cdot 38$ & $15 \cdot 35$ & 2.96 \\
\hline Fat (g) & 78.69 & $21 \cdot 12$ & 71.95 & $19 \cdot 00$ \\
\hline Energy from fat (\%) & $38 \cdot 19$ & $10 \cdot 25$ & $36 \cdot 30$ & $9 \cdot 58$ \\
\hline Saturated fat $(\mathrm{g})$ & $23 \cdot 21$ & $11 \cdot 17$ & $22 \cdot 42$ & $6 \cdot 55$ \\
\hline $\begin{array}{l}\text { Energy from } \\
\text { saturated fat (\%) }\end{array}$ & $11 \cdot 26$ & $5 \cdot 42$ & $11 \cdot 31$ & $3 \cdot 30$ \\
\hline MUFA (g) & 29.97 & $8 \cdot 30$ & $28 \cdot 79$ & $8 \cdot 41$ \\
\hline Energy from MUFA (\%) & 14.54 & 4.03 & 14.52 & $4 \cdot 24$ \\
\hline PUFA (g) & 11.58 & $5 \cdot 59$ & $9 \cdot 43$ & 3.93 \\
\hline Energy from PUFA (\%) & $5 \cdot 62$ & $2 \cdot 71$ & $4 \cdot 76$ & 1.98 \\
\hline Cholesterol (mg) & $262 \cdot 36$ & $181 \cdot 37$ & $266 \cdot 76$ & $115 \cdot 07$ \\
\hline $\mathrm{CH}(\mathrm{g})$ & $212 \cdot 41$ & $55 \cdot 42$ & $218 \cdot 87$ & $69 \cdot 05$ \\
\hline Energy from $\mathrm{CH}(\%)$ & $45 \cdot 81$ & 11.95 & $49 \cdot 07$ & $15 \cdot 48$ \\
\hline Simple CH (g) & $74 \cdot 30$ & $37 \cdot 72$ & $72 \cdot 03$ & $28 \cdot 05$ \\
\hline $\begin{array}{l}\text { Energy from } \\
\text { simple } \mathrm{CH}(\%)\end{array}$ & $16 \cdot 02$ & $8 \cdot 14$ & $16 \cdot 15$ & $6 \cdot 29$ \\
\hline Polysaccharides (g) & $116 \cdot 63$ & 51.62 & $62 \cdot 95^{\star}$ & $33 \cdot 12$ \\
\hline $\begin{array}{l}\text { Energy from } \\
\text { complex } \mathrm{CH}(\%)\end{array}$ & $25 \cdot 15$ & $11 \cdot 13$ & $14 \cdot 11$ & $7 \cdot 43$ \\
\hline Dietary fibre (g) & $19 \cdot 52$ & $10 \cdot 78$ & $17 \cdot 56$ & $9 \cdot 13$ \\
\hline
\end{tabular}

$\mathrm{CH}$, carbohydrates.

* Mean value was significantly different from that before the GFD $(P<0.05$; Student's $t$ test). 
Table 2. Composition of the faecal microbiota of healthy adults before and after following a gluten-free diet (GFD) analysed by fluorescent in situ hybridisation (FISH) and flow cytometry detection (FCM) $†$

(Medians and interquartile ranges (IQR))

\begin{tabular}{|c|c|c|c|c|c|}
\hline \multirow[b]{2}{*}{ Microbial group } & \multicolumn{2}{|c|}{$\begin{array}{l}\text { Adults under standard diet } \\
\qquad(n 10)\end{array}$} & \multicolumn{2}{|c|}{$\begin{array}{l}\text { Adults under GFD diet } \\
\qquad(n 10)\end{array}$} & \multirow[b]{2}{*}{$P$} \\
\hline & Median & IQR & Median & IQR & \\
\hline Atopobium & 6.09 & $3.46-9.60$ & $3 \cdot 35$ & $1.8-4.87$ & 0.122 \\
\hline Bifidobacterium & $11 \cdot 14$ & $7 \cdot 64-16 \cdot 70$ & $5 \cdot 12$ & $3.92-8.51$ & $0.007^{*}$ \\
\hline Lactobacillus-Enteroccoccus & 2.58 & $1.34-3.50$ & 0.78 & $0.56-2.66$ & 0.058 \\
\hline Bacteroides-Prevotella & 5.99 & $3.21-9.49$ & $2 \cdot 05$ & $1.54-6.61$ & 0.102 \\
\hline Escherichia coli & 6.08 & $3.46-10.56$ & 8.42 & $4 \cdot 21-12 \cdot 21$ & 0.501 \\
\hline Eubacterium rectale-Clostridium coccoides & $6 \cdot 56$ & $4 \cdot 19-20 \cdot 15$ & 4.52 & $1.81-9.77$ & 0.122 \\
\hline Clostridium histolyticum & $7 \cdot 87$ & $3.99-12 \cdot 01$ & 6.93 & $3.72-10.47$ & 0.753 \\
\hline Clostridium lituseburense & $5 \cdot 39$ & $3.44-8.02$ & 3.43 & $1.41-4.21$ & $0.031^{*}$ \\
\hline Faecalibacterium prausnitzii & $13 \cdot 77$ & $8 \cdot 37-17.98$ & 5.08 & $4 \cdot 41-7 \cdot 20$ & $0.009^{*}$ \\
\hline
\end{tabular}

${ }^{*} P<0.05$ (Mann-Whitney $U$ test).

† Data are group-specific bacterial proportions related to total population detected with the EUB universal probe as determined by FCM-FISH.

Bacteroides-Prevotella, Eubacterium rectale-C. coccoides and C. histolyticum group proportions were slightly reduced, while those of Escherichia coli were increased after the GFD but not significantly (Table 2). Total counts determined by FISH using 4',6-diamidino-2-phenylindole also showed significant reductions after the GFD from 10.25 to $9.98 \mathrm{log}$ cells/g faeces $(P=0 \cdot 030)$. The composition of the faecal microbiota analysed by qPCR is shown in Table 3. Individual baseline variability of bacterial populations expressed as median of differences in $\log$ cells per $\mathrm{g}$ faeces was as follows: 0.37 (IQR $0 \cdot 17-0.65$ ) for Bifidobacterium; 1.50 (IQR 0.21-1.68) for Bacteroides; 0.40 (IQR 0.08-0.82) for C. coccoides; 0.27 (IQR 0.13-1.05) for C. leptum; 0.27 (IQR 0.33-0.37) for C. histolyticum; 0.87 (IQR 0.20-1.13) for Lactobacillus; 0.48 (IQR 0.24-1.18) for Escherichia coli; 0.80 (IQR 0.15-1.37) for Enterobacteriaceae. The counts of Bifidobacterium and Lactobacillus groups decreased significantly after the GFD $(P=0.020$ and $P=0.001$, respectively), while those of Escherichia coli $(P=0.003)$ and total Enterobacteriaceae $(P<0.005)$ significantly increased as a result of the GFD, following a similar trend as that detected by FISH. Total counts were also reduced after the GFD when determined by qPCR from 9.85 to $9.71 \mathrm{log}$ cells/g faeces $(P=0.089)$, following the same trend as by FISH quantification. Therefore, introduction of a GFD implied a reduction in bacterial populations generally regarded as beneficial for human health such as Bifidobacterium and Lactobacillus, and an increase in those of opportunistic pathogens such as Escherichia coli and total Enterobacteriaceae. These changes could be related to reductions in polysaccharide intake, since these dietary compounds usually reach the distal part of the colon partially undigested, and constitute one of the main energy sources for beneficial components of the gut microbiota ${ }^{(27)}$. In addition, reductions in Bifidobacterium and Lactobacillus populations relative to Gram-negative bacteria (Bacteroides and Escherichia coli) were previously detected in untreated $\mathrm{CD}$ children and particularly in treated $\mathrm{CD}$ patients with a $\mathrm{GFD}^{(7)}$. These findings

Table 3. Composition of the faecal microbiota of healthy adults before and after following a gluten-free diet (GFD) analysed by quantitative PCR $\dagger$ (Medians and interquartile ranges (IQR))

\begin{tabular}{|c|c|c|c|c|c|c|c|}
\hline \multirow[b]{2}{*}{ Microbial group } & \multicolumn{3}{|c|}{ Adults under standard diet $(n 10)$} & \multicolumn{3}{|c|}{ Adults under GFD diet ( $n$ 10) } & \multirow[b]{2}{*}{$P$} \\
\hline & Prevalence $\ddagger$ & Median & IQR & Prevalenceł & Median & IQR & \\
\hline Bifidobacterium & 10 & 8.85 & $7 \cdot 84-9 \cdot 24$ & 10 & 7.79 & $7.43-8.45$ & $0.020^{*}$ \\
\hline Bacteroides & 10 & $8 \cdot 61$ & $8.03-9.20$ & 10 & $8 \cdot 21$ & $7 \cdot 25-9.21$ & 0.450 \\
\hline Clostridium coccoides & 10 & 9.44 & $8 \cdot 51-10 \cdot 11$ & 10 & 9.52 & $8.73-9.92$ & 0.983 \\
\hline Clostridium leptum & 10 & 9.54 & $9 \cdot 18-10 \cdot 31$ & 10 & $10 \cdot 11$ & $9 \cdot 81-10.52$ & 0.141 \\
\hline Clostridium histolyticum & 10 & $5 \cdot 70$ & $5 \cdot 17-6 \cdot 34$ & 10 & 6.48 & $5 \cdot 13-6 \cdot 59$ & 0.223 \\
\hline Lactobacillus & 10 & 7.73 & $7.10-7.98$ & 10 & $7 \cdot 00$ & $6 \cdot 25-7 \cdot 64$ & $0.001^{*}$ \\
\hline Escherichia coli & 10 & $6 \cdot 29$ & $5 \cdot 67-6 \cdot 77$ & 10 & $7 \cdot 40$ & $6.83-7.96$ & $0.003^{*}$ \\
\hline Enterobacteriaceae & 10 & $6 \cdot 64$ & $5.86-7.99$ & 10 & $8 \cdot 16$ & $7.41-8.42$ & $0.005^{*}$ \\
\hline \multicolumn{8}{|l|}{ Bifidobacterium species } \\
\hline Bifidobacterium longum & 10 & $7 \cdot 73$ & $7.61-8.62$ & 10 & $7 \cdot 32$ & $6.54-7.79$ & $0.017^{*}$ \\
\hline Bifidobacterium breve & 8 & 4.72 & $4.47-5.94$ & 8 & 5.00 & $4.60-5.56$ & 0.757 \\
\hline Bifidobacterium bifidum & 10 & $6 \cdot 75$ & $6 \cdot 73-6 \cdot 76$ & 10 & $6 \cdot 75$ & $6 \cdot 75-6 \cdot 85$ & 0.208 \\
\hline Bifidobacterium adolescentis & 7 & $5 \cdot 71$ & $4.83-8.65$ & 8 & 6.73 & $5.39-7.80$ & 0.975 \\
\hline Bifidobacterium catenulatum & 10 & $6 \cdot 81$ & $6.05-8.4$ & 10 & $6 \cdot 66$ & $5 \cdot 88-8.13$ & 0.538 \\
\hline Bifidobacterium angulatum & 5 & 5.00 & $4 \cdot 95-5 \cdot 24$ & 5 & $5 \cdot 35$ & $5.06-5.42$ & $0.038^{*}$ \\
\hline Bifidobacterium lactis & 6 & 5.82 & $5 \cdot 21-6 \cdot 58$ & 5 & 4.89 & $4.62-5.63$ & 0.201 \\
\hline
\end{tabular}

${ }^{*} P<0.05$ (Mann-Whitney $U$ test).

†Data are log cell number/g faeces.

$\ddagger$ Prevalence reflects the number of positive amplifications from total samples analysed by quantitative PCR. 
indicate that this dietary therapy may contribute to reduce beneficial bacterial group counts and increase enterobacterial counts, which are microbial features associated with the active phase of $\mathrm{CD}^{(7,28)}$ and, therefore, it would not favour completely the normalisation of the gut ecosystem in treated CD patients. The relative proportion of $F$. prausnitzii was also significantly reduced after the GFD in healthy adults following a similar trend as that detected in untreated or treated CD patients compared with controls $^{(7)}$. A depletion of $F$. prausnitzii population in faecal mucus of active Crohn's disease patients has also been detected, leading to an inverse relationship between the abundance of this population and inflammatory bowel disorders ${ }^{(29)}$. Bifidobacterium species composition was also analysed under the effect of the GFD by qPCR (Table 3). Individual baseline variability of bacterial populations expressed as median of differences in log cells/g faeces was as follows: 0.71 (IQR 0.08-1.33) for Bifidobacterium longum; 0.68 (IQR 0.07-1.03) for B. breve; 1.16 (IQR 0.77-1.07) for B. bifidum; 0.86 (IQR 0.17-1.29) for B. adolescentis; 1.21 (IQR 0.63-1.72) for B. catenulatum; 0.30 (IQR 0.002-0.45) for B. angulatum; 0.35 (IQR 0.19-0.82) for $B$. lactis. The counts of $B$. angulatum were significantly increased $(P=0.038)$ after the GFD, while those of B. longum decreased $(P=0.017)$, indicating that this species contributed to the reduction detected in total Bifidobacterium population (Table 3 ).
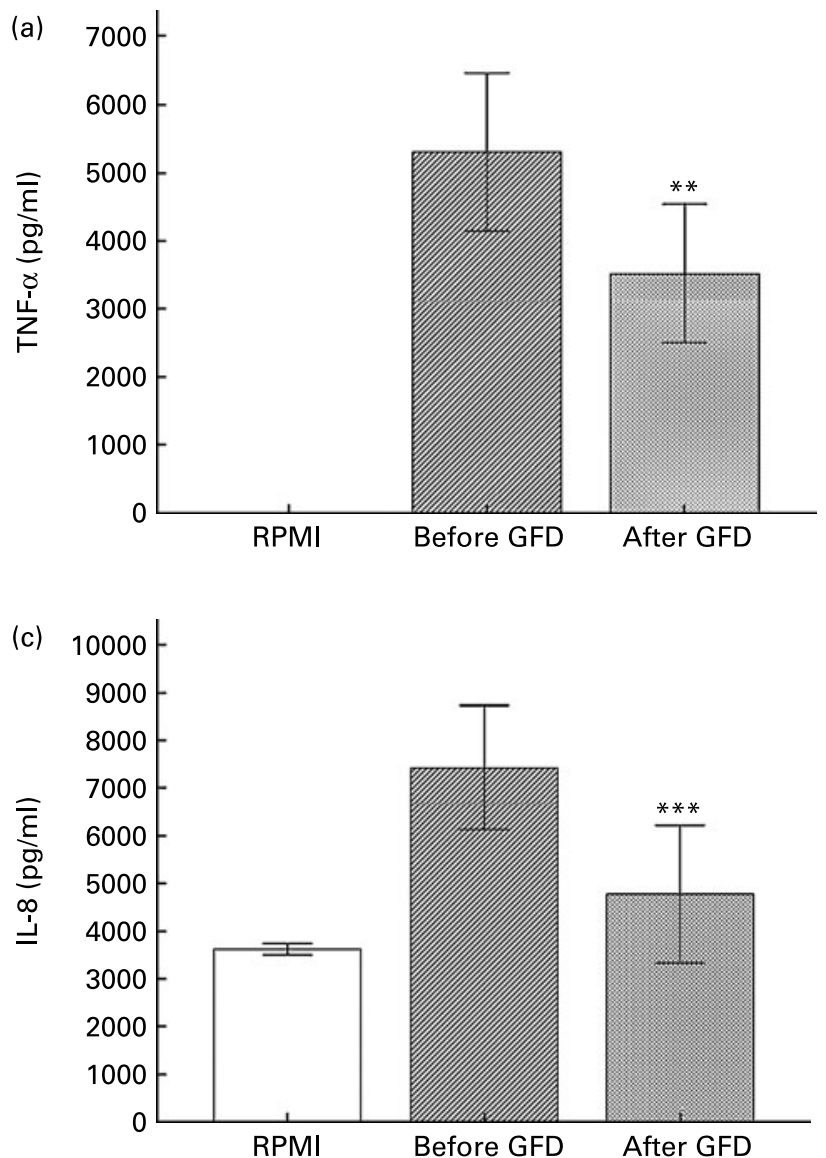

The genome sequence of B. longum subsp. longum showed that more than $8 \%$ of the annotated genes were involved in carbohydrate and polysaccharide metabolism ${ }^{(30)}$, which could explain the reduction of their levels after the GFD, parallel with a reduction in polysaccharide intake.

\section{Gluten-free diet influences immunostimulatory activity of the intestinal microbiota}

Changes in cytokine production patterns stimulated by faecal samples of healthy individuals after and before the GFD are shown in Fig. 1. Immunostimulatory properties of the colonic content of these individuals, representing an altered microbiota, were remarkably reduced after following a GFD, inducing a significantly lower production of the pro-inflammatory cytokines TNF- $\alpha(P=0.021)$ and IFN- $\gamma(P=0.037)$ and the chemokine IL-8 $(P=0.007)$. Thus, a GFD could contribute to reduce the pro-inflammatory signals in the gut by introducing modifications in the microbiota structure. In addition, the faecal samples of individuals under a GFD induced significantly lower production of the anti-inflammatory cytokine IL-10 $(P=0.002)$ than those of individuals on a standard gluten-containing diet. IL-10 inhibits the production of pro-inflammatory and Th1 cytokines such as
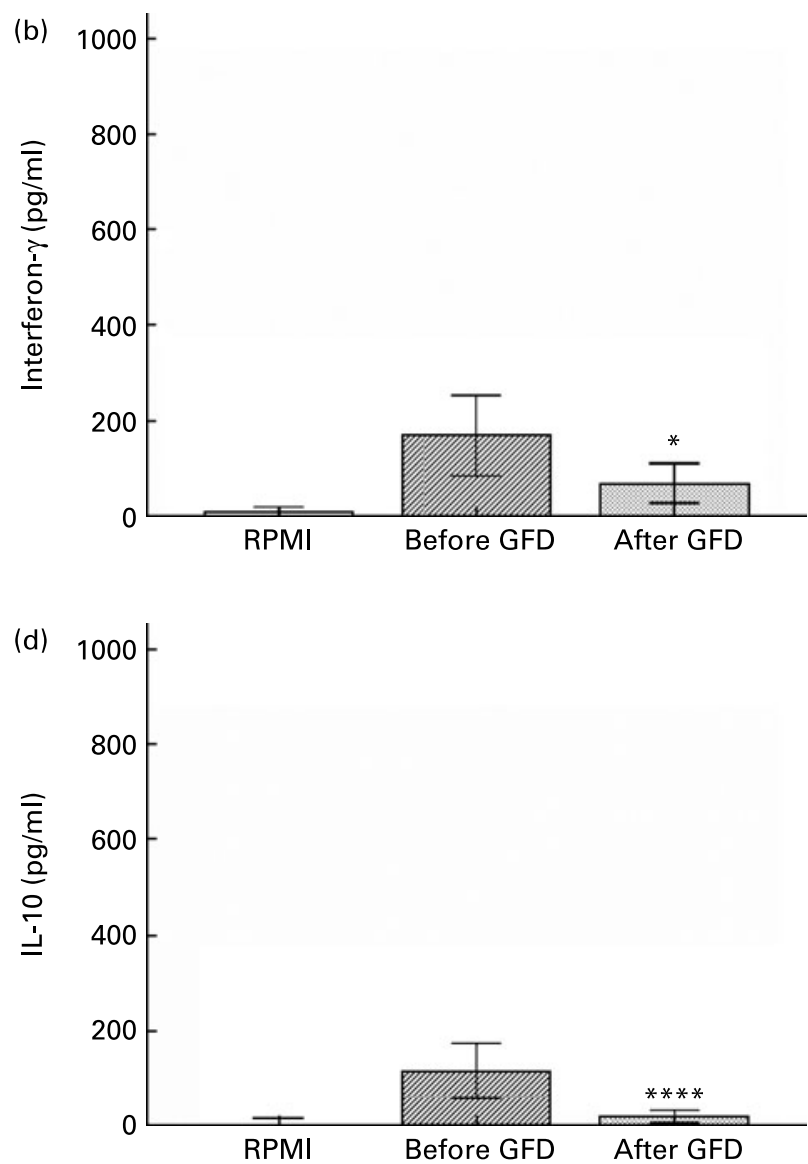

Fig. 1. Cytokine production (TNF- $\alpha$ (a), interferon- $\gamma$ (b), IL-8 (c), IL-10 (d)) by peripheral blood mononuclear cells (PBMC) stimulated with faecal samples from healthy volunteers before and after the gluten-free diet (GFD) and controls (non-stimulated PBMC). Results are expressed as means of duplicate measures determined in four independent experiments, with standard deviations represented by vertical bars. Statistically significant differences were established by applying Student's $t$ test at $P<0.050$. RPMI, Roswell Park Memorial Institute medium. Mean value was significantly different from that before the GFD:

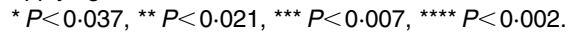


TNF- $\alpha$ and IFN- $\gamma^{(31)}$. Therefore, it could be expected that reductions in Th1-type cytokine production were accompanied by increases in the Th2-type and regulatory cytokine IL-10. However, when a stimulus increases IFN- $\gamma$ production, IL-10 production can also be increased by counter-regulatory mechanisms and vice versa. In this case, it seems likely that GFD led to a generalised reduction of bacterial-induced cytokine production in vitro as a result of the generalised reduction caused by this dietary intervention in the total luminal bacterial load of the large intestine. Moreover, specific bacterial group changes could also be partially responsible for the differences detected in cytokine induction since, for instance, Bifidobacterium genus and particularly some $B$. longum strains have been acknowledged for their ability to stimulate IL-10 production ${ }^{(25)}$ and their levels were significantly reduced after the GFD. The immune-suppressive effects associated with the GFD may be partly beneficial for CD patients, which are prone to a Th1-biased immune response, but may also imply a defect of their defence and regulatory mechanisms against harmful antigens and chronic inflammation.

\section{Conclusions}

The obtained results suggest that a GFD may influence the composition and immune function of the gut microbiota in healthy individuals, without the influence of any underlying disease, parallel with reductions in polysaccharide intake. Although this is a preliminary short-term intervention study, bacterial changes are similar to those detected previously in children after compliance with a long-term GFD. As intestinal bacteria constitute a constant challenge of antigens to their host that modulate immunity, the GFD should be considered as a possible environmental factor that may shape the microbiota composition and gut health in treated CD patients.

\section{Acknowledgements}

The present study was supported by grants AGL2008-01 440/ ALI and Consolider Fun- $C$-Food CSD2007-00 063 from the Spanish Ministry of Science and Innovation.

G. D. P. and M. C. C. were recipients of I3P scholarships from the Spanish National Research Council (CSIC, Spain) and I. N. from Generalitat Valenciana (Spain) and CSIC (200570F0091).

G. D. P. carried out the immunological and statistical analyses. I. N. and M. C. C. carried out the microbiological analyses. Y. S. conceived of and coordinated the study, and wrote the manuscript. All authors read, reviewed and approved the final version of the manuscript.

The authors do not have any conflict of interest.

\section{References}

1. Marsh MN (1992) Gluten, major histocompatibility complex, and the small intestine. A molecular and immunobiologic approach to the spectrum of gluten sensitivity ('celiac sprue'). Gastroenterology 102, 330-354.

2. Sollid LM (2002) Coeliac disease: dissecting a complex inflammatory disorder. Nat Rev Immunol 2, 647-655.

3. Gianfrani C, Auricchio S \& Troncone R (2005) Adaptive and innate immune responses in celiac disease. Immunol Lett 99, 141-145.
4. Cinova J, Palová-Jelínková L, Smythies LE, et al. (2007) Gliadin peptides activate blood monocytes from patients with celiac disease. J Clin Immunol 27, 201-209.

5. Cosnes J, Cellier C, Viola S, et al. (2008) Incidence of autoimmune diseases in celiac disease: protective effect of the gluten-free diet. Clin Gastroenterol Hepatol 6, 753-758.

6. Malandrino N, Capristo E, Farnetti S, et al. (2008) Metabolic and nutritional features in adult celiac patients. Dig Dis 26, $128-133$.

7. Nadal I, Donat E, Ribes-Koninckx C, et al. (2007) Imbalance in the composition of the duodenal microbiota of children with coeliac disease. J Med Microbiol 56, 1669-1674.

8. Sanz Y, Sánchez E, De Palma G, et al. (2008) Indigenous gut microbiota, probiotics, and coeliac disease. In Child Nutrition and Physiology, pp. 210-224 [LT Overton and MR Ewente, editors]. Hauppauge, NY: Nova Science Publishers.

9. Elder JH, Shankar M, Shuster J, et al. (2006) The gluten-free, casein-free diet in autism: results of a preliminary double blind clinical trial. J Autism Dev Disord 36, 413-420.

10. Farran A, Zamora R \& Cervera P (2004) Tablas de Composición de Alimentos CESNID (CESNID Food Composition Tables), 2nd ed. Barcelona: McGraw-Hill/Interamericana.

11. Collado MC, Calabuig M \& Sanz Y (2007) Differences between the fecal microbiota of coeliac infants and healthy controls. Curr Issues Intest Microbiol 8, 9-14.

12. Amann RI, Binder BJ, Olson RJ, et al. (1990) Combination of 16S rRNA-targeted oligonucleotide probes with flow cytometry for analyzing mixed microbial populations. Appl Environ Microbiol 56, 1919-1925.

13. Harmsen HJM, Wildeboer-Veloo AC, Grijpstra J, et al. (2000) Development of 16S rRNA based probes for the Coriobacterium group and the Atopobium cluster and their application for enumeration of Coriobacteriaceae in human feces from volunteers of different age. Appl Environ Microbiol 66, 4523-4527.

14. Langendijk PS, Schut F, Jansen GJ, et al. (1995) Quantitative fluorescence in situ hybridization of Bifidobacterium spp. with genus specific 16S rRNA-targeted probes and its application in fecal samples. Appl Environ Microbiol 61, 3069-3075.

15. Harmsen HJH, Gibson GR, Elfferich P, et al. (1999) Comparison of viable cell counts and fluorescence in situ hybridization using specific rRNA-based probes for the quantification of human fecal bacteria. FEMS Microbiol Lett 183, 125-129.

16. Manz W, Amann R, Ludwig W, et al. (1996) Application of a suite of 16S rRNA-specific oligonucleotide probes designed to investigate bacteria of the phylum Cytophaga-flavobacter-bacteroides in the natural environment. Microbiology 142, 1097-1106.

17. Poulsen LK, Lan F, Kristensen CS, et al. (1994) Spatial distribution of Escherichia coli in the mouse large intestine inferred from rRNA in situ hybridization. Infect Immun 62, 5191-5194.

18. Franks AH, Harmsen HJM, Raangs GC, et al. (1998) Variations of bacterial populations in human faeces measured by fluorescent in situ hybridization with group specific $16 \mathrm{~S}$ rRNA-targeted oligonucleotide probes. Appl Environ Microbiol 64, 3336-3345.

19. Hold GL, Schwiertz A, Aminov RI, et al. (2003) Oligonucleotide probes that detect quantitatively significant groups of butyrate-producing bacteria in human feces. Appl Environ Microbiol 69, 4320-4324.

20. Suau A, Rochet V, Sghir A, et al. (2001) Fusobacterium prausnitzii and related species represent a dominant group within the human fecal flora. Syst Appl Microbiol 24, 139-145.

21. Wallner G, Amann R \& Beisker W (1993) Optimizing fluorescent in situ hybridization with rRNA-targeted oligonucleotide probes for flow cytometric identification of microorganisms. Cytometry 14, 136-143.

22. Collado MC \& Sanz Y (2007) Quantification of mucosaadhered microbiota of lambs and calves by the use of culture 
methods and fluorescent in situ hybridization coupled with flow cytometry techniques. Vet Microbiol 121, 299-306.

23. Matsuki T, Watanabe K, Fujimoto J, et al. (2002) Development of 16S rRNA-gene-targeted group-specific primers for the detection and identification of predominant bacteria in human feces. Appl Environ Microbiol 68, 5445-5451.

24. Malinen E, Kassinen A, Rinttilä T, et al. (2003) Comparison of real-time PCR with SYBR Green I or $5^{\prime}$-nuclease assays and dot-blot hybridization with rDNA-targeted oligonucleotide probes in quantification of selected faecal bacteria Microbiology 149, 269-277.

25. Medina M, Izquierdo E, Ennahar S, et al. (2007) Differential immunomodulatory properties of Bifidobacterium longum strains: relevance to probiotic selection and clinical applications. Clin Exp Immunol 150, 531-538.

26. Kinsey L, Burden ST \& Bannerman E (2008) A dietary survey to determine if patients with coeliac disease are meeting current healthy eating guidelines and how their diet compares to that of the British general population. Eur $J$ Clin Nutr 62, 1333-1342.

27. De Graaf AA \& Venema K (2008) Gaining insight into microbial physiology in the large intestine: a special role for stable isotopes. Adv Microb Physiol 53, 73-168.

28. Collado MC, Donat E, Ribes-Koninckx C, et al. (2009) Specific duodenal and faecal bacterial groups associated with paediatric coeliac disease. J Clin Pathol 62, 264-269.

29. Swidsinski A, Loening-Baucke V, Vaneechoutte $\mathrm{M}$, et al. (2007) Active Crohn's disease and ulcerative colitis can be specifically diagnosed and monitored based on the biostructure of the fecal flora. Inflamm Bowel Dis 14, 147-161.

30. Schell MA, Karmirantzou M, Snel B, et al. (2002) The genome sequence of Bifidobacterium longum reflects its adaptation to the human gastrointestinal tract. Proc Natl Acad Sci U S A 99, $14422-14427$.

31. Mosmann TR (1994) Properties and functions of interleukin-10. Adv Immunol 56, 1-26. 